\title{
Learner Motivation and Engagement in Virtual EFL Classes at Tertiary Level during the Pandemic
}

\author{
Nishat Tasneem \\ Department of English, International Standard University \\ Dhaka-1212, Bangladesh \\ nishat@,isu.ac.bd \\ Article History: Submitted on 14 ${ }^{\text {th }}$ April 2021; Accepted on $7^{\text {th }}$ June 2021; \\ Published on $30^{\text {th }}$ June 2021
}

\begin{abstract}
In the face of the ongoing pandemic crisis in the country, the tertiary level education context of Bangladesh has predominantly resorted to online and distance learning modules. While such virtual English as Foreign Language (EFL) classes have undoubtedly played a pivotal role to ensure the continuation of tertiary level teaching and learning even amidst the closure of educational institutions in the country, however, some contemporary research and news in this regard have reported on tertiary level learners' dissatisfaction and reduced performances in such EFL classes. As such, to assess the learners' perceived motivation and engagement in virtual EFL classes, the current research uses a mixed-method approach. Here, the researcher uses questionnaire survey, interview and FGD guidelines, constructed based on Vroom's expectancy theory of motivation and instruments to assess attitude orientation, to collect data from both the "target" group, i.e. the learners, and the "resource" group, i.e. the teachers and the parents, from 5 tertiary level institutes of the country. Here, the data highlights negative attitude and reduced motivation orientation of the learners towards certain aspects in online EFL classes. The findings also manifest some imperial causal factors, which lead to reduced motivation and engagement of learners in such online modules. Thus, it unravels how online education has exacerbated the digital divide among learners amidst the pandemic crisis. Moreover, the study also presents some pedagogic participantcentric suggestions to promote motivation and engagement of the learners in online EFL classes in a developing country context like Bangladesh.
\end{abstract}

Keywords: Motivation, EFL, Virtual Classrooms, Tertiary Level, Pandemic 


\section{INTRODUCTION}

Online classroom manifests a different module of education that provides the same opportunities for the teaching and learning process beyond the physical limits of the traditional classroom through web-based learning modes (Hsu et al., 1999). Thus, the learner-centered educational opportunities with virtual language classrooms could satisfy multimodal learners' needs, reduce dependency on rote learning, and enhance experiential learning in the process of language teaching and learning. However, despite some of these positive highlights, the virtual language classroom, like the physical ones, entails different challenges in terms of logistics, costing, liability, accessibility, userfriendliness, teacher training, time management, lack of technological competency and proficiency, lack of pair and group work activities. (Kluge \& Riley, 2008; Gillett-Swan, 2017).

Like other countries, the Government of Bangladesh (GoB)'s lockdown restrictions have closed down all educational institutions in the country since 18 March 2020. As a result, 42 million students can no longer attend educational institutions physically and might be prevented from doing so for an indefinite period (UNICEF, 2020). Immediately after the closure, GoB encouraged and instructed the schools, colleges and universities to initiate online classes for their students. In response, many universities have started taking online classes by using available means, such as WeChat, Zoom, Google Meet, for tertiary level students. However, taking such online classes for tertiary-level English as Foreign Language (EFL) education is not without hindrances in a developing country like Bangladesh, as the technology and equipment required to participate in such online classes are not cheap. It requires the availability of technological infrastructures like internet connection and computers or smartphones with cameras for both the teachers and the students. The rise of internet cost and minimum required gadgets for participating in online classes is also beyond most students in a developing country like Bangladesh.

Due to such drawbacks in online education, there have been enhanced reports on tertiary level learners' decreased learning performances and interest in online modules amidst the Pandemic (Dutta \& Smita, 2020; Emon et al., 2020). Research reveals a significant lack of preparedness, participation, and less scope of classroom activities through online learning. Furthermore, problems with feasible consistency of the internet and electricity, lack of learners' attention persistence, comprehension in online modules were also cited as affecting factors for such a decrease in learners' understanding and interest in such virtual classes (Al-Amin et al., 2021). Here, although a significant proportion of the research in this regard has reported on such decreased learning process and performances in online modules in Bangladesh due to the persisting challenges, however, there is a lack of research, which explores the motivation orientation and causal factors affecting such orientation in online EFL classes among tertiary level learners in Bangladesh during the Pandemic. The current study attempts to address this gap in the study by exploring the 
causes of such reduced motivation levels through a mixed-method research study.

Motivation is noted as an attribute that gives energy to behavior and reinforces it to direct and sustain it. Motivation involves beliefs, perceptions, values, information and actions that are interrelated to each other. Motivation can affect behaviors and, thus, it is essential to understand the importance and impact of such motivation in an educational setting (Brophy, 2010). Contemporary studies link motivation to an individual's cognitive and affective processes such as thoughts, beliefs, perspectives, goals and emotions. In a pedagogic context, motivation can be affected by various social and contextual factors (Schunk, et al., 2014). According to Suhag et al. (2016), motivation has several effects on the learning and behavior of the students. Motivation sets specific goals that students strive for and, thus, influences the choices of the students. Motivation also increases the effort and energy to determine whether a student will pursue a difficult task with enthusiasm or with an indifferent attitude. Regarding the learners' motivation in online classes, many studies have shown that the effective use of e-learning or online learning could help increase students' motivation, engagement, and attendance in the classes (Harandi, 2015; Hartnett, 2016). In this regard, extrinsic and intrinsic goal orientation, selfefficacy, effective teacher instruction, use of scaffolding technique, real-time feedback were cited as aspects that increase learners' motivation in the online pedagogic process (Samir et al., 2014; Lee \& Martin, 2017; Gedera et al., 2015 ).

In this study, Victory Vroom's (1964) expectancy theory was primarily used to understand the perceived motivation level of the learners. The expectancy theory of motivation is a cognitive theory of motivation, which entails that an individual will behave or act in a certain way because they are motivated to select a specific behavior over others based on that selected behaviour. In other words, the motivation of the behavior selection is determined by the desirability of the outcome. Accommodating the theory to an educational environment suggests that the amount of motivation and effort a student will put into learning will depend on three perceptual relationships: (1) Expectancy: This refers to the "effort-performance" relation. Thus, the perception of the students that the effort that he or she will put forward will result in the attainment of the "performance" increases their motivation in the classroom process. This cognitive evaluation is heavily weighted by a student's experiences, personality, confidence etc. Teachers should understand this connection between effort and performance and its impact on motivation; (2) Instrumentality: This refers to the "performance-reward" relation. The students evaluate the likelihood or probability that achieving the performance level will result in the attainment of the reward. If the reward is much more, then performance will be better and if it is less, then motivation will decrease and, lastly, (3) Valence: It means the value the students place on each of the outcomes, i.e. what are the rewards, and will they satisfy the learners' needs? Teachers should find out what those specific needs and rewards are. All these factors need to be present to influence motivation. 
Again, assessing the learners' attitude orientation is required if we need to understand the learners' motivation orientation. Prior studies have shown that attitude has been identified as an essential factor that affects learners' motivation, interests, and performances in online learning environments (Zhu et al., 2020; Dörnyei, 2003; Selvi, 2010). Furthermore, Yang and Cornelius' (2004) qualitative research showed learners' positive attitude in some aspects of online classes, e.g., flexibility, cost-effectiveness, electronic research availability, ease of connection to the internet, and well-designed class interface. On the other hand, it highlighted negative attitudes towards other aspects, e.g., delayed feedback from instructors, unavailable technical support from instructors, lack of agency and self-motivation, monotonous instructional methods, and poorly designed course content. In this regard, it can be ascertained that there is a directly proportional relationship between a learners' attitude orientation and motivation orientation concerning an aspect. If the attitude is negative, motivation will also be less and if it is positive, then motivation will also be more with an aspect. Apart from this, to understand the motivation level of learners in the online EFL sphere, it is imperative that we take into consideration other factors, including-the proportion of conducive learning atmosphere in such online classes (Krahnke \& Krashen, 1983); use of effective strategies, such as lesson study., by teachers to create a positive learning process and environment which caters to learners' attention, confidence, satisfaction (Aimah et al., 2016); variable factors like the environment, curriculum as well as teaching-learning factors, such as- teacher support, learner satisfaction, classroom activities . (Tuan, 2012; Yilmaz et al., 2017; Kebritchi \& Santiague, 2017).

Prior research studies have reported on an association between learners' decreased motivation in online classes with lack of feasible internet network, teacher and peer interaction, learning materials at home as well as with issues like complexity to remember read lessons, decrease in overall study time etc. (Dutta \& Smita, 2020; Meo et al., 2020). However, there is a lack of research, which conducts a comprehensive study on the causal factors affecting motivation orientation, primarily in the tertiary level virtual EFL context in Bangladesh during the Pandemic. Here, EFL pedagogic context in Bangladesh can be manifested as a specialized field encumbered by its own set of challenges about learners' motivation, participation, and performances (Rahman et al., 2019). These challenges are further exacerbated amidst the pandemic crisis. The current research attempts to address the gap by conducting a comprehensive research study on the situational and cognitive causal factors affecting learners' motivation in the online EFL classes at the tertiary level in Bangladesh during the Pandemic through a small-scale pedagogic participant-oriented study based on the selected cognitive theory of motivation along with other scales and instruments to measure the dynamics of attitude and motivation of the learners. The study also attempted to unravel some pedagogic participant-oriented recommendations regarding enhancing the learners' motivation in the online EFL pedagogic context at the tertiary level in Bangladesh. 


\section{METHOD}

The research is a mixed-method study, and it utilizes both quantitative and qualitative research process and analysis as demonstrated in Figure 1. The data was collected during the Pandemic, thus, it utilized the following three data collection instruments: online survey questionnaires, telephone/Zoom interviews and online focus group discussions (FGD) (Morgan, 1997). Questionnaire surveys manifest an efficient way to collect information from many research participants in a short time (Brown, 1995). Again, Dilshad and Latif (2013) assert that interview sessions provide "a setting for the relatively homogeneous group to reflect on the questions asked by the interview" and is crucial for collecting qualitative data (pp.191-93). Furthermore, according to Morgan (1997), focus group discussions are crucial instruments to obtain a collective notion of the participants' subjective opinions regarding an issue, event or topic. Here, a mixed-method approach was adopted for the study as prior research in learners' motivation orientation studies adopts both qualitative and quantitative approaches (Hartnett et al., 2011; Selvi, 2010) and ensuring proper triangulation of data.

Figure 1:

Diagram Representing Data Collection and Analysis Steps

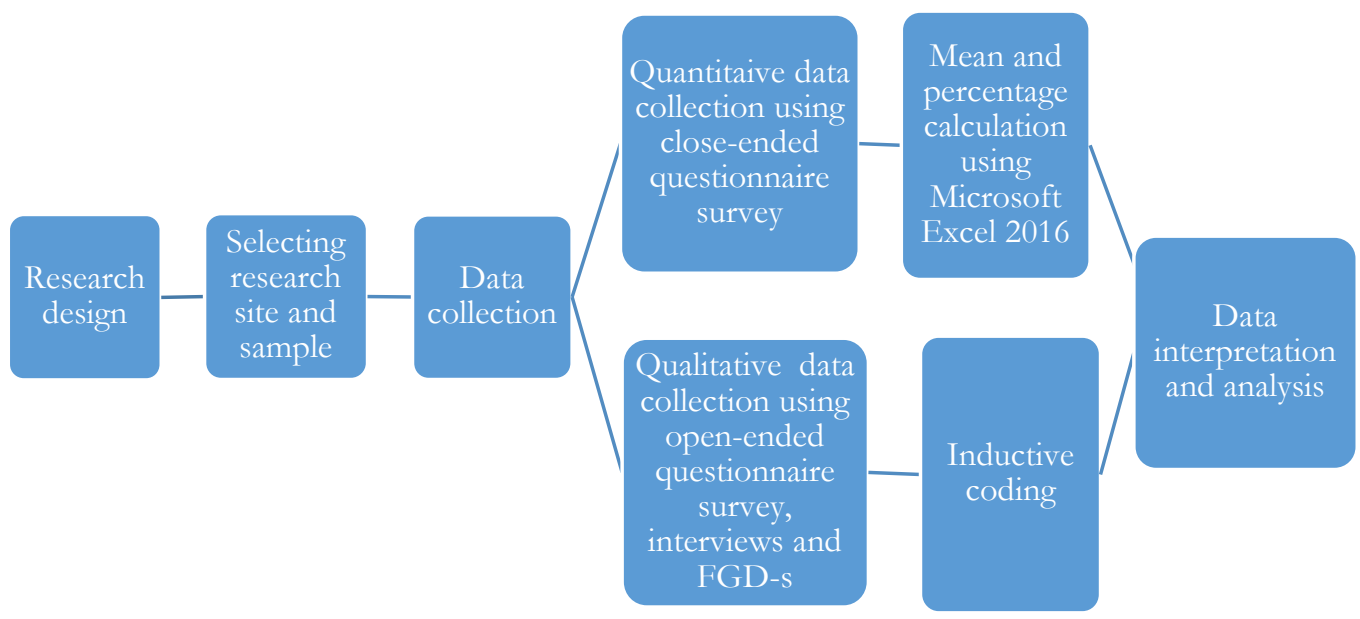

Here, the research was conducted among five tertiary level private universities of Dhaka city, the capital of the country, and the research sample included both "target group" i.e. the students and the "resource group" i.e. the teachers and the parents (Brown, 1995). The universities were selected by purposive sampling based on the information that the universities are conducting online EFL classes amidst the Pandemic. Here, the age of the target group ranged between 18-21 years and included students from year 1 of the 
University level education, as EFL classes are mostly offered during the first year of tertiary education in Bangladesh. Here, the students were from different subject backgrounds, including- business administration, engineering, law, natural sciences, and male and female students. In addition, the teachers who take these EFL classes were selected for the interview, and the parents of the particular "target group" were interviewed. In total, the sample size included 251 students, 9 teachers and 12 parents.

Here, the research instruments were designed based on Vroom's (1964) expectancy theory of motivation and based on an adapted version of Yang and Cornelius' (2004) interview questionnaires for assessing the learners' perceptions and attitudes towards online classes. As such, the students' semistructured questionnaire statements were constructed primarily based on Vroom's expectancy theory and were measured through Likert's measurement index. The survey also contained a subjective opinion segment after each question statement. The qualitative instruments were primarily based on the adapted version of Yang and Cornelius' (2004) interview questionnaire and assessed the learners' attitude and, thereby, their motivation in online modules. The interview and FGD guidelines also included questions to unravel the research participants' perceptions regarding the reasons that affect such motivation orientation of the learners and their suggestions to improve such motivation orientation in online EFL teaching-learning context. Here, all the quantitative question item responses were analysed through Microsoft Excel 2016. The mean of the responses was then interpreted based on Likert's index. The close ended survey questionnaire items contained five criteria index based on Likert's scale, i.e. agree, partially agree, neutral, disagree and partially disagree. The qualitative data from the subjective opinion segment of the questionnaire, the interviews and the FGDs were inductively coded through listening and reading intensively (Gibbs, 2007) to the recorded contents. The findings from the qualitative data is presented through direct quotation as well as pie diagram and table format in the following segment of the paper.

\section{FINDINGS AND DISCUSSION}

This section will highlight some imperial findings regarding motivation orientation and causal factors affecting the learners' motivation level and some pedagogic participant-oriented suggestions to enhance learner motivation and participation in the online EFL modules. Here, in the expectancy-oriented survey statement, most of the learners responded that they agree or partially agree that they have a role to play in the predicted outcome, i.e., their performance in online classes and exams. If the event seems random or outside the individual's control, students will feel less motivated to pursue that course of action. On the other hand, if the students play a significant role in success, students will feel more instrumental and intrinsically motivated. Figure 1, which represents the learners' responses to the expectancy-oriented survey statement, highlights that most of the students agree or partially agree that their 
performances and learning outcomes in the online EFL classes depend on their endeavors and participation. However, one student in the subjective opinion segment asserted -"I know I can do better in online English classes if I tried more. However, due to internet disruptions, lack of effective classroom process, technology access. we sometimes become helpless and miss the online classes. It makes us lose motivation as we do not have any control over the internet and other technical aspects needed for online classes." This entails that the students perceive a close association between their endeavors and expected performances in online EFL modules. However, such expectancy ratio is lowered when outside the control spectrum of the learners, such as internet, technology access, budget., comes into play in the particular context.

Figure 2:

Learners' Expectancy Proportions in Online EFL Classes

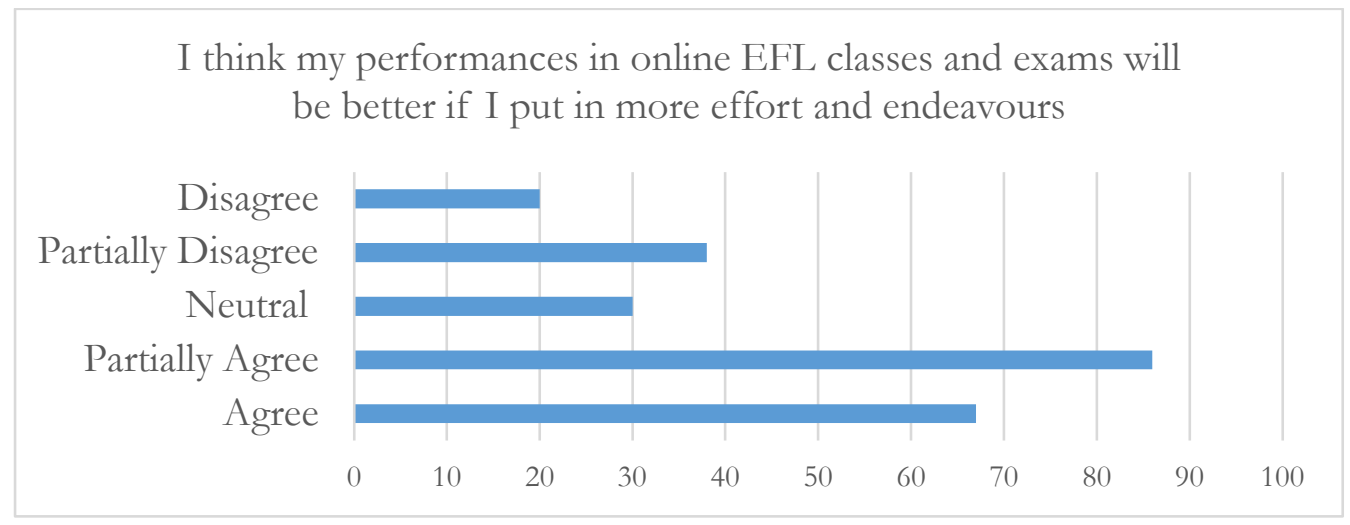

Moreover, in the instrumentality-oriented survey statement, most of the learners asserted that they disagree or partially disagree that their performances and participation in online EFL classes and exams are adequately rewarded. Here, if the students perceive that achieving the performance level will result in the attainment of the reward, they will be more interested in the online learning process. On the other hand, if the reward is lacking, then their instrumentality proportion will also decrease and, thereby, decrease the extrinsic motivation of the learners. Therefore, as manifested in Figure 2, most students disagree or partially disagree that their performances and participation are adequately valued in online EFL modules. In this regard, one student in the subjective opinion segment asserted that "Instant feedbacks and error corrections are slow in online English modules. In the physical classes, our participation and performances were more praised and reinforced by the teachers. In the online modules, such encouragements in the feedback process is low and slow. As there are time management problems and technical issues thus, the teacher is only focused on completing the lessons within the small time span. We also get less in online summative and formative assessments as compared to the physical ones." In this regard, another student noted that- "In the physical classes, the teacher could provide reinforcement and praises to the students one by one. However, online classes have less time and is encumbered by different technical 
problems. As such, the teacher is unable to provide individual reinforcement through feedbacks. As such, the students often feel like their participations are not adequately recognized and reinforced." Thus, the data reveals the learners' perceptions, which entails that their efforts, performances, and participation are less encouraged and reinforced in the online classes than the physical ones.

Figure 3:

Learners' Instrumentality Proportions in Online EFL Classes

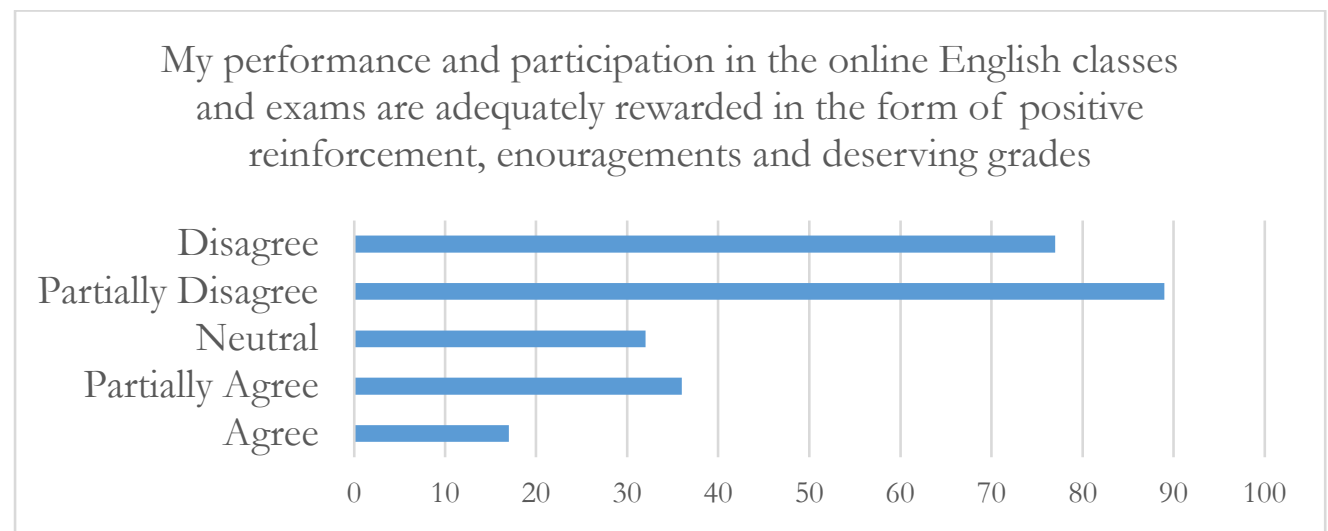

Regarding valence proportion, the students' responses show a poor valence rate. Figure 3 shows that most students partially and disagree entirely that online EFL classes positively impact their English language learning process. In this regard, the subjective opinion segment of the question highlighted some imperial findings, including-" "Online learning does not provide opportunity to practice speaking and writing like physical classes"; "Online learning is not as effective as physical classes"; "I do not think online learning is effective because it does not develop language skills adequately and does not provide enough interaction opportunities in English"; "I do not think online learning is effective as I have problems with content comprehension and retention" etc. As such, the findings highlight that learners generally think that online EFL classes have less benefit in improving their English language skills and abilities than the physical EFL classes. Here, things that seem unlikely to produce personal benefit have a low valence, while those with immediate personal rewards have a higher valence proportion. As the learners mostly think that online EFL classes do not benefit their individual English learning process and outcomes, the findings show a low valence proportion. 
Figure 4:

Learners' Valence Proportions in Online EFL Classes

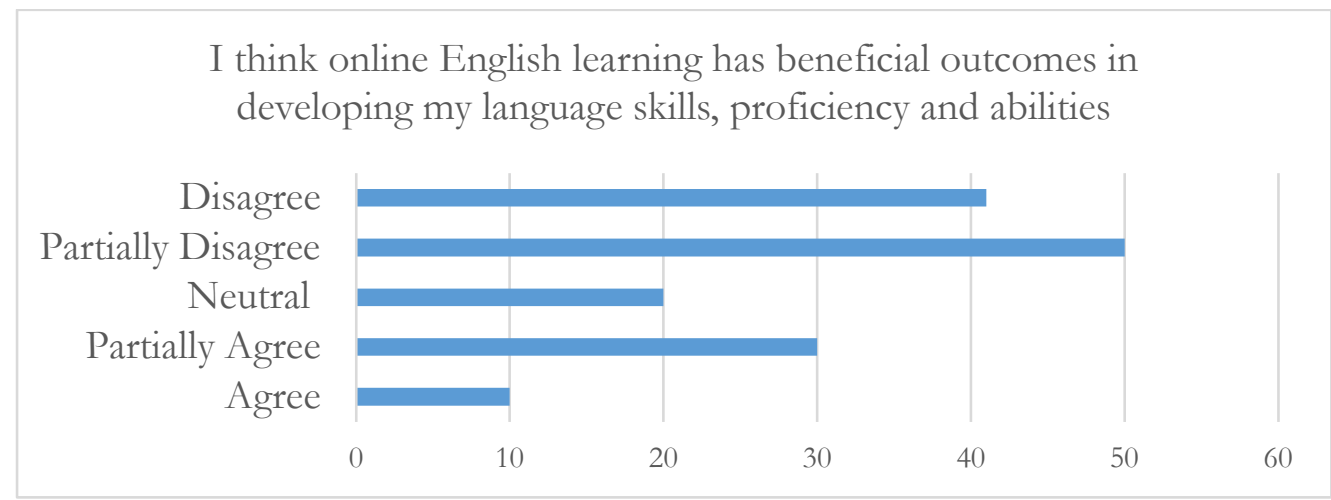

Although the learners' expectancy proportion is comparatively high in this case, the survey reveals a low valence and instrumentality rate. Based on the studies mentioned above, we know that all three of these factors need to be present to influence motivation. It is required that teachers have an in-depth understanding of students in all three areas or survey them in advance to identify them. If a student is highly motivated, all three factors of the expectancy model need to be high. If even one of these factors is less (e.g., expectancy is high, but instrumentality and valence is low), the student will have less motivation for the course of the module. A low proportion in valence and expectancy scale in the study highlights the reasons behind reduced motivation level among the tertiary level students in online EFL modules.

Again, to understand the motivation orientation of the learners, it is essential to understand their attitude orientation towards such classes. Thus, three FGD, consisting of 10 learners each, and interviews with 9 teachers and 12 parents were conducted to unravel the learners' attitude towards online classes. Here, both the interview and the FGD findings asserted that the learners prefer traditional EFL classes over the online EFL modules. Here, students in one of the FGD sessions manifested that -"We do not like online classes. It is not as efficient as traditional classes. The teaching is inefficient, and the learning is slow. In addition, there is a lack of adequate support and quality insurance of online classes." Similar notions were noted in other FGDs and in the teachers' and parents' interviews as well. Based on the interview and FGD findings, the learners' attitudes towards online learning environment, quality of online teaching-learning process, technical and other support provided in online classes, online feedback and error correction, course content as well as assessments, after coding, were noted to be mostly negative in nature and this can be presented through the following diagram: 
Figure 5:

Findings from FGD-s and Interviews regarding Learners' Attitudes towards Online EFL Classes

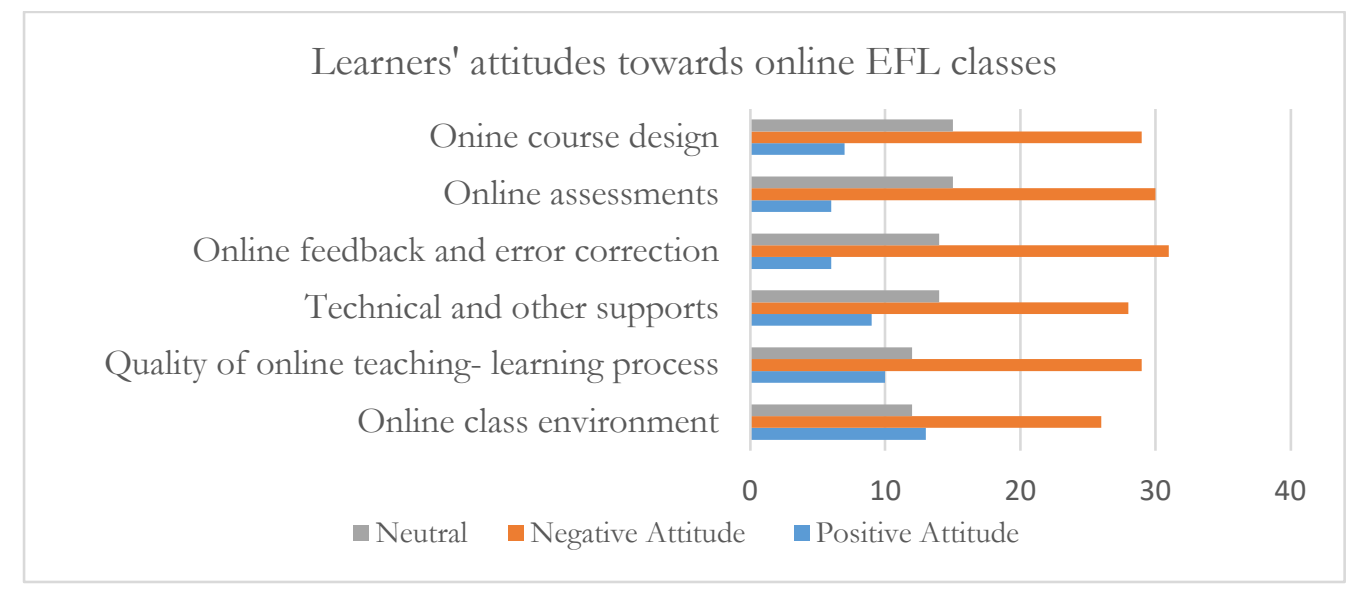

This negative attitude towards different segments in online EFL classes reduces learners' motivation towards the online EFL classes. Some of these negative attitudes towards the online pedagogic process hold similarities with the research mentioned above about learners' attitude orientation. Here, the FGD and interview participants were further inquired regarding the causal aspects, which results in such negative attitude and, thereby, reduced motivation level of the learners towards online EFL classes. In response to the reasons behind the reduced motivation orientation of learners towards online EFL classes, the FGD and interview findings highlighted issues with course, technology, context and teaching and learning-oriented factors, which causes such reduce motivation level among the learners. In this regard, one of the FGD findings asserted the following factors, which affect their motivation in online classes-

There are many aspects in online English classes which makes us demotivated towards it. Technology oriented factors, such as internet disruptions, technology access etc. are some of them. We get less interaction and practice opportunities as the teachers often give us one-directional instruction of grammar rules and vocabulary over zoom. In physical classes, we used to get more interaction opportunities in English and the feedbacks and corrections were instant. The course contents are not properly adapted to online modules and the learning is not as interactive as it used to be in the physical classes. Before we used to get practice of all the four skills in the integrated English classes. Now, we barely get any listening and speaking practices. Moreover, most of the parents have negative attitudes towards online classes, which further reduces our motivation.

Furthermore, interview with one teacher manifested the following aspects, which affect the learners' motivation in online classes-

Online EFL classes are not as effective as physical classes and, thus, the students have reduced motivation and negative attitude towards online classes. 
There are issues with time management, technological disruptions etc. in online classes. As such, we cannot provide enough interaction opportunities for the learners in online modules and the feedback process is slow as well. Online learning is slow and, thus, we face difficulty finishing the course syllabus. Furthermore, as the assessments are not properly adapted to the online modules, therefore, we see a high proportion of plagiarism in online examinations. There are also issues with student and teacher harassment and misconduct in online classes.

In this regard, one parent interview also entailed similar findings, which leads to such reduced motivation in online English classes-

My son's performances have undoubtedly diminished in online English classes. I do not see him attending the classes or taking the examinations seriously. This reduced motivation can be because online classes are new and still not acceptable to the learners who have always been used to physical class modules. Furthermore, my son also complains that teaching is not effective in online classes and the teachers only manifest a one-directional teaching in online classes.

Here, the interviews and FGDs further highlighted that online modules have increased the "Digital Divide" (Khalid \& Pedersen, 2016) at the tertiary level as socio-economic condition determines learners' better access to technology and internet facilities thereby, better motivation and performances in online classes. In this regard, one FGD findings reveal -

Those who are rich and living in urban spheres have better access to technology and internet. Therefore, they can attend the classes regularly and more effectively. The ones who are from middle-income families and are currently leaving in rural and remote setting do not have that privilege. If you have the access and means, your motivation towards online classes will be high. If you do not, it will be low.

In this regard, the aforementioned qualitative data findings entail that the teaching-learning oriented factors for reduced motivation consist of issues like lack of interest and agency in online learning, lack of expertise and knowledge in technology usage, lack of training in online module, etc. These aspects further act as a causal factor for lack of participation and engagement in online modules and poor performance in online assessments. Here, the course oriented factors primarily entailed issues like lack of adaptability of existing EFL course contents, activities and assessments to online modules and the context-oriented factors mainly highlighted issues like negative attitudes of learners, parents, teachers and administrative personnel towards such classes as well as harassment, misbehaviours and lack of acceptance of online education modules by some learners. Finally, in regard to technology-oriented factors, the issues entail low internet bandwidth and high cost of IT and internet facilities, lack of access to technologies in remote regions etc. Based on the FGD and the interview findings, it was ascertained that such aspects act as causal factors in such reduced motivation and negative attitude towards the online EFL modules 
and hold similarities with the research mentioned above regarding motivation orientation. Therefore, based on the findings, the factors can be deduced into specific criteria as follows:

Table 1:

Causal Factors affecting Motivation Orientation in Online EFL Classes

\begin{tabular}{|c|l|}
\hline \multicolumn{1}{|c|}{ Criteria } & \multicolumn{1}{c|}{ Issues } \\
\hline $\begin{array}{c}\text { Teacher/learner-oriented } \\
\text { factors }\end{array}$ & $\begin{array}{l}\text { Lack of agency of learners in classroom process } \\
\text { lack of expertise and knowledge in technology } \\
\text { use } \\
\text { Lack of monitoring, feedback and error } \\
\text { correction } \\
\text { Lack of interactive and integrated skills classes }\end{array}$ \\
\hline $\begin{array}{c}\text { Course-oriented Factors } \\
\text { Unadapted EFL course contents and materials } \\
\text { Unadapted EFL activities and tasks } \\
\text { Unadapted assessments }\end{array}$ \\
\hline $\begin{array}{l}\text { Technology-oriented } \\
\text { factors }\end{array}$ & $\begin{array}{l}\text { Negative attitude of stakeholders } \\
\text { Misconduct/ harassment } \\
\text { Lack of socio-economic capabilities } \\
\text { Availability } \\
\text { Affordability }\end{array}$ \\
\hline
\end{tabular}

Again, from the qualitative data findings, a series of pedagogicparticipant and stakeholder-oriented suggestions were unraveled to improvise the online EFL modules and enhance the learners' engagement and motivation in the online classes. The suggestions also entailed aspects, which can help to bring about improvement in the aforementioned criteria of teaching, learning, course, context and technology-oriented factors, which determines the learners' motivation orientation in online modules. Here, this can be manifested as follows: 
Figure 6:

Suggestions for Enhancing Learners' Motivation in Online EFL Modules

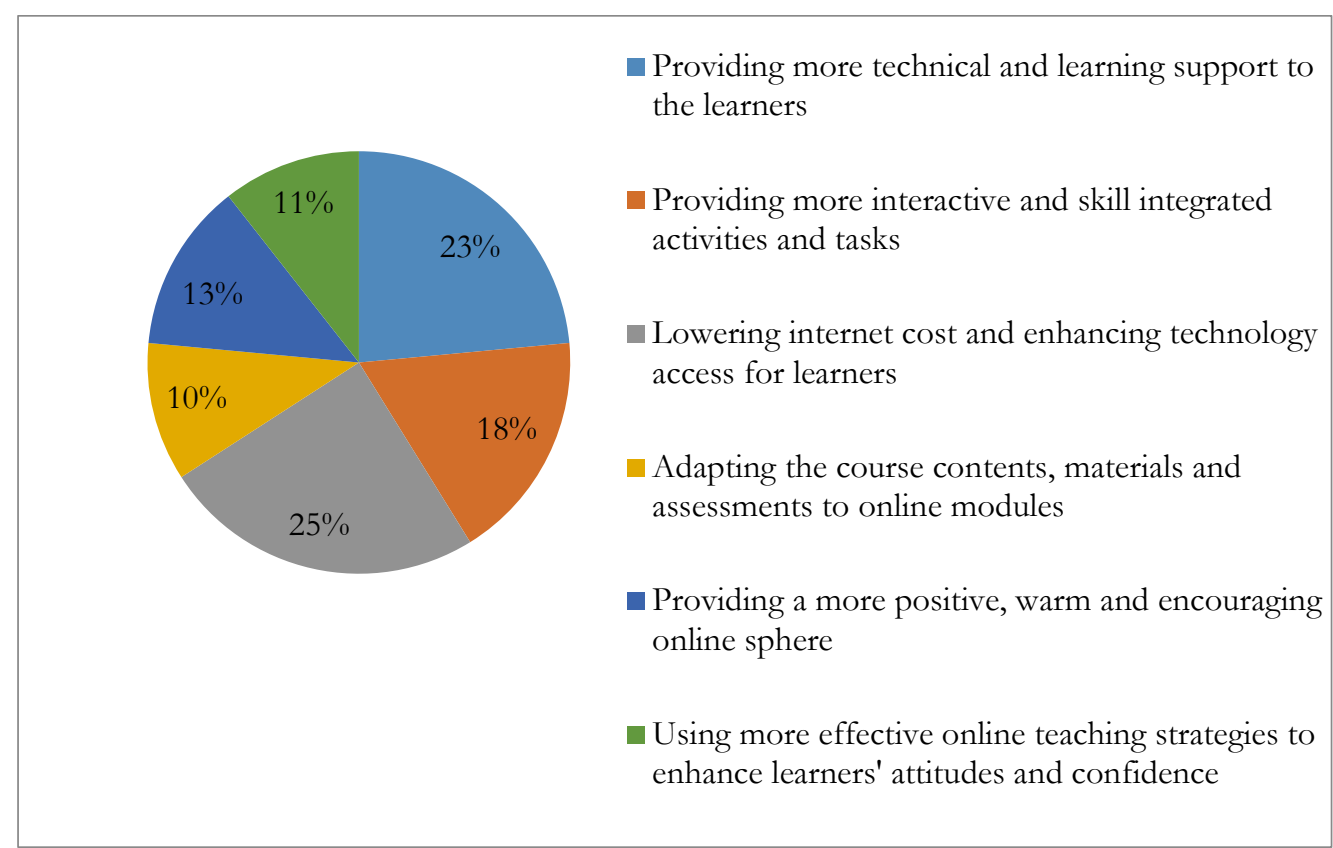

Here, it can be observed that the suggestions primarily aimed at lowering the drawbacks as mentioned above about course, technology, contextual and teaching-learning oriented factors of online modules, which act as causal factors for reduced learner motivation in the online EFL classes. It also indirectly aimed at providing a more conducive learning atmosphere, which can increase teaching and learning efficiency in online EFL modules in order to increase the proportion of learners' valence, expectancy and instrumentality in online EFL classes by providing a more encouraging and participatory atmosphere; inducing more interactive and skill integrated language activities. Furthermore, incorporating the suggestions can also help nurture a positive attitude of the learners towards the online EFL classes in terms of teaching, learning, instructional quality, assessments, etc.

\section{CONCLUSION}

The paper assesses the motivation orientation of the tertiary level learners. It highlights some important causal factors that lead to reduced motivation and participation of the learners in the online EFL modules, taking place in the contemporary pandemic-affected context of a developing country Bangladesh. While the research highlights a lack of valence and instrumentality proportion of the learners, it also highlights a series of aspects that act as causal factors for the learners' reduced motivation and negative attitude towards the online modules. Identifying such aspects is essential as teachers and administrative personnel of tertiary level educational institutes need to identify which aspects of learners' needs and cognition are being overlooked in the online classes and, 
thereby, triggering the low level of learners' motivation in the online classes modules. Finally, the paper presents some pedagogic participant-oriented suggestions, which can be used as guiding tools for teachers, at the micro level, and policymakers, at the macro level, to bring about changes and improvement in the contemporary dimension of online EFL modules at the tertiary level in a developing country context like Bangladesh. The empirical findings can also guide more large-scale future research in the area of learner motivation and engagement in online EFL classes amidst the Pandemic.

\section{REFERENCES}

Aimah, S., Ifadah, M., Wijayatiningsih, T. D., Yuliasri, I., \& Bharati, D. A. L. (2016). Lesson study: A way to enhance students motivation in learning process in the classroom. Lensa: Kajian Kebahasaan, Kesusastraan, dan Budaya, 6(1), 93-104. http://103.97.100.145/index.php/lensa/article/view/1923/1963

Al-Amin, M., Zubayer, A. Al, Deb, B., \& Hasan, M. (2021). Status of tertiary level online class in Bangladesh: Students' response on preparedness, participation and classroom activities. Heliyon, 7(1), 1-7. https://doi.org/10.1016/j.heliyon.2021.e05943

Brophy, J. (2010). Motivating students in classrooms. In P. Peterson, E. Baker, \& B. McGaw (Eds.), International Encyclopedia of Education (pp. 624-630). Elsevier. https://doi.org/10.1016/b978-0-08-044894-7.00613-8

Brown, J. D. (1995). The elements of language curriculum: A systematic approach to program development. Heinle \& Heinle Publishers.

Dilshad, R. M., \& Latif, M. I. (2013). Focus group interview as a tool for qualitative research: An analysis. Pakistan Journal of Social Sciences (PJSS), 33(1), 191-198. https://www.bzu.edu.pk/PJSS/Vol33No12013/PJSSVol33-No1-16.pdf

Dutta, S., \& Smita, M. K. (2020). The impact of COVID-19 Pandemic on tertiary education in bangladesh: Students' perspectives. Open Journal of Social Sciences, 8(9), 53-68. https://doi.org/10.4236/jss.2020.89004

Dörnyei, Z. (2003). Attitudes, orientations, and motivations in language learning: Advances in theory, research, and applications. Language Learning , 53 (1), 3-32. https://doi.org/10.1111/1467-9922.53222

Emon, E. K. H., Alif, A. R., \& Islam, M. S. (2020). Impact of COVID-19 on the institutional education system and its associated students in 
Bangladesh. Asian Journal of Education and Social Studies, 34-46. https://doi.org/10.9734/ajess/2020/v11i230288

Gedera, D., Williams, J., \& Wright, N. (2015). Identifying factors influencing students' motivation and engagement in online courses. In Motivation, Leadership and Curriculum Design (pp. 13-23). Springer Singapore. https://doi.org/10.1007/978-981-287-230-2 2

Gibbs, G. R. (2007). Analyring Qualitative Data. SAGE Publications, Ltd https://www.doi.org/10.4135/9781849208574

Gillett-Swan, J. (2017). The challenges of online learning: Supporting and engaging the isolated learner. Journal of Learning Design, 10(1), 20. https://doi.org/10.5204/jld.v9i3.293

Harandi, S. R. (2015). Effects of e-learning on students' motivation. Procedia Social and Behavioral Sciences, 181, 423-430. https://doi.org/10.1016/j.sbspro.2015.04.905

Hartnett, M. (2016). The importance of motivation in online learning. In Motivation in Online Education (pp. 5-32).Springer Singapore. https://doi.org/10.1007/978-981-10-0700-2 2

Hartnett, M., St. George, A., \& Dron, J. (2011). Examining motivation in online distance learning environments: Complex, multifaceted, and situation-dependent. The International Review of Research in Open and Distance Learning, 12(6), 20-38. https://doi.org/10.19173/irrodl.v12i6.1030

Hsu, S., Marques, O., Hamza, M. K., \& Alhalabi, B. (1999). How to design a virtual classroom: 10 easy steps to follow. T.H.E. Journal, 27(2), 96-98. https://www.learntechlib.org/p/89341/

Kebritchi, M., \& Santiague, L. (2017). Issues and challenges for teaching successful online courses in higher education: A literature review. Journal of Educational Technology Systems, 46(1), 4-29. https://doi.org/10.1177/0047239516661713

Khalid, M. S., \& Pedersen, M. J. L. (2016). Digital exclusion in higher education contexts: A systematic literature review. Procedia - Social and Behavioral Sciences, 228, 614-621.

https://doi.org/10.1016/i.sbspro.2016.07.094

Kluge, S., \& Riley, L. (2008). Teaching in virtual worlds: Opportunities and challenges. Issues in Informing Science and Information Technology, 5, 127-135. https://doi.org/10.28945/1000 
Krahnke, K. J., \& Krashen, S. D. (1983). Principles and practice in second language acquisition. TESOL Quarterly, 17(2), 300-305. https://doi.org/10.2307/3586656

Lee, J., \& Martin, L. (2017). Investigating students' perceptions of motivating factors of online class discussions. International Review of Research in Open and Distance Learning, 18(5). https://doi.org/10.19173/irrodl.v18i5.2883

Meo, S. A., Abukhalaf, A. A., Alomar, A. A., Sattar, K., \& Klonoff, D. C. (2020). Covid-19 Pandemic: Impact of quarantine on medical students' mental wellbeing and learning behaviors. Pakistan Journal of Medical Sciences, 36(COVID19-S4). https://doi.org/10.12669/pjms.36.COVID19-S4.2809

Morgan, D. L. (1997). Focus Groups as Qualitative Research. SAGE Publications, Inc. https://www.doi.org/10.4135/9781412984287

Rahman, M. M., Islam, M. S., Karim, A., Chowdhury, T. A., Rahman, M. M., Seraj, P. M. I., \& Singh, M. K. M. (2019). English language teaching in Bangladesh today: Issues, outcomes and implications. In Language Testing in Asia 9, 9. https://doi.org/10.1186/s40468-019-0085-8

Samir Abou El-Seoud, M., Taj-Eddin, I. A. T. F., Seddiek, N., El-Khouly, M. M., \& Nosseir, A. (2014). E-learning and students' motivation: A research study on the effect of e-learning on higher education. International Journal of Emerging Technologies in Learning, 9(4), 20. https://doi.org/10.3991/ijet.v9i4.3465

Schunk, D., Meece, J., \& Pintrich, P. (2014). Motivation in Education: Theory, Research, and Applications: International Edition ( $4^{\text {th }}$ ed.). Pearson.

Selvi, K. (2010). Motivating factors in online courses. Procedia - Social and Behavioral Sciences, 2(2), 819-824. https://doi.org/10.1016/j.sbspro.2010.03.110

Suhag, A. K., Larik, R. S. A., Tagar, A. A., \& Solangi, S. R. (2016). Student academic motivation of secondary schools of Khairpur Mir's. Academic Research International, 7(1), 100-109. http://paper.researchbib.com/view/paper/69817

Tuan, L. T. (2012). An empirical research into EFL learners' motivation. Theory and Practice in Language Studies, 2(3), 430-439. https://doi.org/10.4304/tpls.2.3.430-439 
UNICEF. (2020, May 06). Students in Bangladesh adjust to remote learning via national TV during COVID-19 lockdown.

https://www.unicef.org/bangladesh/en/stories/students-bangladeshadjust-remote-learning-national-tv-during-covid-19-lockdown

Victor H.V. (1964). Work and motivation. Wiley.

Yang, Y., \& Cornelius, L. F. (2004). Students' perceptions towards the quality of online education: A qualitative approach. Proceeding of Association for Educational Communications and Technology, 861-877. https://www.learntechlib.org/p/76937/

Yilmaz, E., Şahin, M., \& Turgut, M. (2017). Variables affecting student motivation based on academic publications. Journal of Education and Practice, 8(12), 112-120. https://files.eric.ed.gov/fulltext/EJ1140621.pdf

Zhu, Y., Zhang, J. H., Au, W., \& Yates, G. (2020). University students' online learning attitudes and continuous intention to undertake online courses: a self-regulated learning perspective. Educational Technology Research and Development, 68(3), 1485-1519. https://doi.org/10.1007/s11423-020$\underline{09753-\mathrm{W}}$ 